\title{
The Effect of Magnaporthe oryzae Conidia on Photosystem in Rice
}

\author{
Jun Yi, Yungao Hu, Ling Zhang, Guotao Yang, and Liqiong Tang
}

\begin{abstract}
Investigation of the effect of Magnaporthe oryzae on rice to breed resistant varieties is important to environment protection to reduce the use of chemical pesticides. Investigation of the effects of $M$. oryzae conidia on the photosynthesis and photosynthetic pigment contents of rice which plantlets were watered were conducted. The results showed that photosynthesis of rice was inhibited by stomatal and non-stomatal factors in rice which treated by $M$. oryzae conidia. The different rice responded to various $M$. oryzae physiological races were found to be statistically different. The $\mathrm{Pn}, \mathrm{E}, \mathrm{Gs}, \mathrm{Ci}$ and $\mathrm{chl} \mathrm{a} / \mathrm{chl} \mathrm{b}$ of the rice restoring line $\mathrm{R} 725$ were decreased significantly by ZA5 and ZA17. The Pn, E, $\mathrm{Gs}, \mathrm{chl} \mathbf{a} / \mathrm{chl} b$ and Car content of the rice restoring line $\mathrm{R} 720$ were decreased significantly by ZC8 and ZF2.The ZF2 also can change significantly the Pn, E, Gs, chl a/chl b and Car content of the rice restoring line $\mathrm{R} 727$.
\end{abstract}

Index Terms-Tillering stage, Magnaporthe oryzae, photosynthesis, photosynthetic pigment.

\section{INTRODUCTION}

Rice blast caused by Magnaporthe oryzae is one of the most serious diseases in paddy rice (Oryza sativa), which restricts the rice production seriously [1]. The use of chemical pesticides result in environmental destruction during controlling, therefore, to understand the relationship between $M$. oryzae and its host is very important to find more environmental prevention measure. Photosynthesis, as the basis of material accumulation in crops, is influenced by various factors, such as light and temperature [2], [3]. Adversity stress (cold, drought, salt) can reduce photosynthetic efficiency significantly and hinder the formation of photosynthetic pigments according to previous study [4], [5]. Some study showed that M. oryzae can change the ultrastructure of leaves in seedlings [6]. The question arising is whether $M$. oryzae conidia have effect on photosynthesis in rice. Now, more researchers use the $M$. oryzae toxins to water the seedlings of rice to research the impact of physiological characteristics, however, it is not better to imitate the process of $M$. oryzae infecting the rice [7]. Here, we study on the effects of $M$. oryzae conidia of five physiological races on the photosynthesis and photosynthetic pigment contents at the tillering stage to provide a theoretical basis for resistance mechanisms of rice blast.

Manuscript received March 4, 2013; revised June 26, 2013. This work was financially supported by the National Science \& Technology Major Projects (2011ZX08001-002) and Key Projects in the National Science \& Technology Pillar Program (2011BAD35B02).

The authors are with Rice research institute of southwest university of science and technology, Mianyang, Sichuan, China (e-mail: donnyj123@163.com, huyungao@swust.edu.cn, zhang ling@swust.edu. cn).

\section{MATERIALS AND METHODS}

Testing materials: three rice restoring lines (R725, R720 and R727) and five $M$. oryzae physiological races (ZA5, $\mathrm{ZA} 17, \mathrm{ZC} 8, \mathrm{ZG1}$ and $\mathrm{ZF} 2$ ), were provided by rice research Institute of Southwest University of Science and Technology. Chemical components of soil consist of full nitrogen was $1.98 \mathrm{~g} / \mathrm{kg}$, available nitrogen was $80.3 \mathrm{mg} / \mathrm{kg}$, available phosphorus was $43.3 \mathrm{mg} / \mathrm{kg}$, and available potassium was $76.2 \mathrm{mg} / \mathrm{kg}$.

Preparation of the fungus conidia: The activated strains of $M$. oryzae were inoculated in oat meal agar medium (oat $30 \mathrm{~g} / \mathrm{L}$ ) at $28^{\circ} \mathrm{C}$. Fungal conidia were harvested by scraping the biomass grown on oat meal agar plates with a sterile surgical blade, and resuspended in sterile water of $0.02 \%$ Tween-20. The sample was diluted for $10^{5}$ spores of $M$. oryzae.

Planting the seedlings and treatment by fungus conidia: Plants were grown in pot culture by direct seeding in experimental station of southwest university of science and technology. Three seedlings in 4 leaves stage were final singled to each pot. The seedling were sprayed $20 \mathrm{ml}$ solution with $10^{5}$ spores of $M$. oryzae for one of physiological race, respectively, with the control of sterile water of $0.02 \%$ Tween-20 at the tillering stage. After spraying, the seedlings would keep humidity for $24 \mathrm{~h}$.

Determination of indexes: Photosynthetic parameters of upper leaves were measured by GFS-3000 photosynthesis from 9:00-11:00 am in clear day at the tillering stage after 7d of spraying. Meanwhile, the content of photosynthetic pigments of the matched parts were determined referred the methods as previous described [8].

\section{RESULTS AND ANALYSIS}

\section{A. The Effect of Conidia from Five M. Oryzae}

Physiological Races on the Photosynthesis

Net photosynthetic rate $(\mathrm{Pn})$ is an important physiological index to evaluate the strength of photosynthesis and crop's prolificacy [9].The results showed that the M. oryzae conidia changed considerably the photosynthetic indexes of leaves at tillering stage. Compared with the control, Pn of plants treated by ZA17, ZC8 and ZF2 conidia decreased by $26.89 \%$, $19.56 \%$ and $18.43 \%$. Especially, the ZF2 conidia reduced Pn of leaves in R725, R720 and R727 significantly, decreased by $16.61 \%, 19.09 \%$ and $18.43 \%$ (Fig. 1a).

Transpiration rate $(\mathrm{E})$ reflects the strength of transpiration and water metabolism status in plants [10]. The conidia, with the exception of ZC8 to R720, reduced the transpiration rate significantly. The ZA5 conidia changed maximumly the Transpiration rate of R725, R720 and R727, decreasing by 
$43.91 \%, 36.56 \%$ and $55.68 \%$ compared with the control (Fig. 1b).

There are two reasons of net photosynthetic rate decreasing. One is stomatal factor, such as the number or size of stoma [11], and the other one is non-stomatal factor, like enzyme activity inside or Photosynthetic components [12]. So if the net photosynthetic rate is decreasing, we may inspect both the stomatal conductance (Gs) and intercellular $\mathrm{CO}_{2}$ concentration $(\mathrm{Ci})$. Compared with the control, Gs of plants treated by ZF2 conidia decreased by $45.05 \%$, $45.03 \%$ and $45.68 \%$, respectively (Fig. 1c). Effect of greatly on $\mathrm{Ci}$ of R725, R720 and R727, were ZC8, ZA17 and ZA5, and increased respectively by $14.67 \%, 4.96 \%$ and $15.75 \%$ (Fig. 1d).

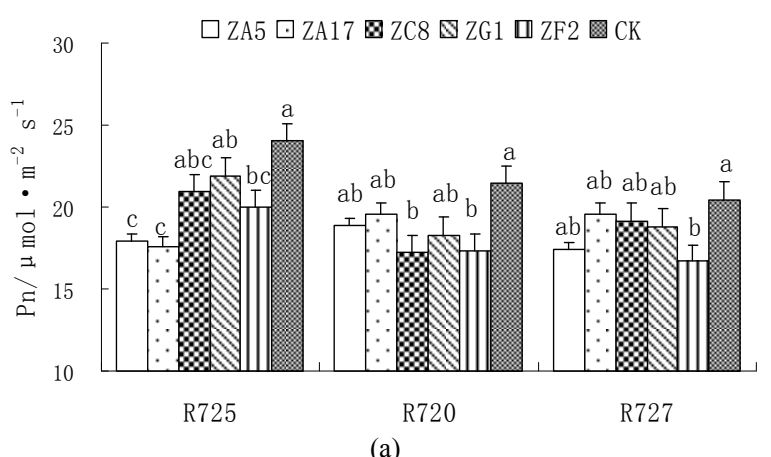

(a)

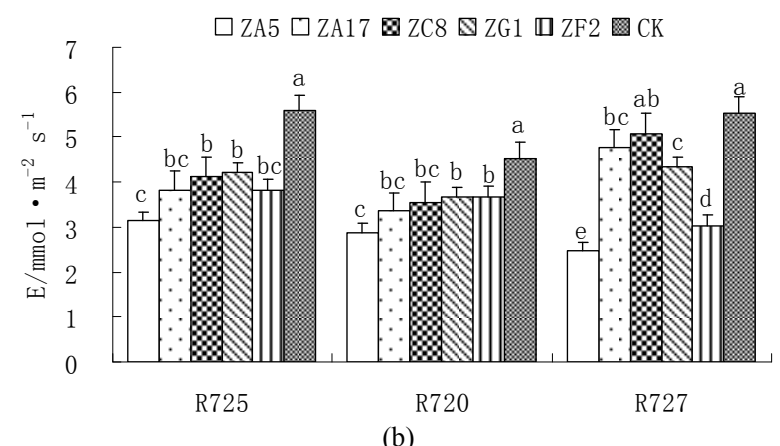

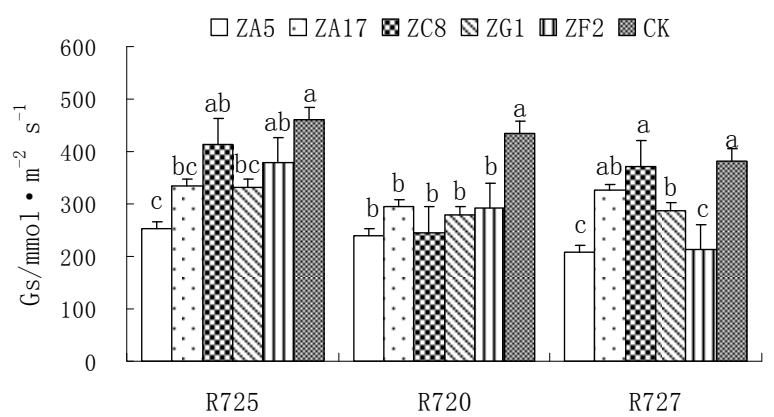

(c)

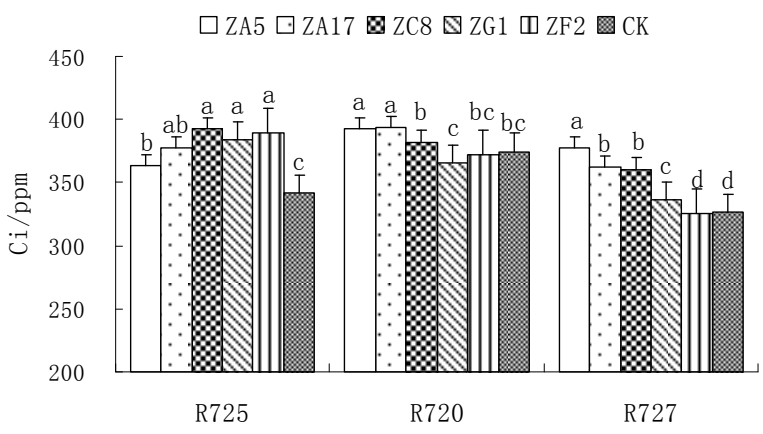

(d)

Fig. 1. Variation of Pn, E, Gs and Ci in rice treated by M. oryzae conidia. Data are means of five biological replicates, with bars showing s.d. Different letters indicate significant difference at $\mathrm{P}<0.05$ by Dunnett's test, using DPS 7.05 software.

\section{B. The Effect of M. Oryzae Conidia of Five Races on the Photosynthetic Pigment Contents}

Photosynthetic pigment was the material basis of photosynthesis, whose content reflect the photosynthetic intensity in plants. M. oryzae conidia could affect photosynthetic pigment contents of leaves in rice in varying degrees. Chl a and Chl b content of R725 treated by ZA5 decreased by $34.47 \%$ and $18.18 \%$, respectively, and Car content of R725 treated by ZC8 decreased by $25.68 \%$.

TABLE I: VARiation of Photosynthetic Pigment Contents In Rice TreAted By M. ORYZAE CONIDIA (MG/KG)

\begin{tabular}{|c|c|c|c|c|c|c|c|}
\hline rice varieties & Index & ZA5 & ZA17 & $\mathrm{ZC} 8$ & ZG1 & $\mathrm{ZF} 2$ & $\mathrm{CK}$ \\
\hline \multirow{5}{*}{$\mathrm{R} 725$} & Chl a & $2.89 \pm 0.07 \mathrm{e}$ & $3.13 \pm 0.07 \mathrm{e}$ & $3.51 \pm 0.27 \mathrm{~d}$ & $4.13 \pm 0.18 b$ & $3.80 \pm 0.11 \mathrm{c}$ & $4.41 \pm 0.09 \mathrm{a}$ \\
\hline & Chl b & $1.44 \pm 0.03 \mathrm{~b}$ & $1.54 \pm 0.11 \mathrm{ab}$ & $1.72 \pm 0.01 \mathrm{a}$ & $1.64 \pm 0.07 \mathrm{ab}$ & $1.53 \pm 0.01 \mathrm{ab}$ & $1.76 \pm 0.02 \mathrm{a}$ \\
\hline & Chl a+b & $4.32 \pm 0.09 \mathrm{e}$ & $4.67 \pm 0.18 \mathrm{~d}$ & $5.23 \pm 0.27 \mathrm{c}$ & $5.78 \pm 0.25 b$ & $5.33 \pm 0.11 \mathrm{c}$ & $6.17 \pm 0.10 \mathrm{a}$ \\
\hline & $\operatorname{chl~a/chl~b~}$ & $2.00 \pm 0.03 \mathrm{~b}$ & $2.10 \pm 0.03 \mathrm{ab}$ & $2.03 \pm 0.02 \mathrm{~b}$ & $2.52 \pm 0.02 \mathrm{a}$ & $2.48 \pm 0.07 \mathrm{a}$ & $2.51 \pm 0.07 \mathrm{a}$ \\
\hline & Car & $0.67 \pm 0.01 \mathrm{ab}$ & $0.66 \pm 0.01 \mathrm{ab}$ & $0.55 \pm 0.04 \mathrm{c}$ & $0.63 \pm 0.01 b$ & $0.66 \pm 0.02 \mathrm{ab}$ & $0.74 \pm 0.01 \mathrm{a}$ \\
\hline \multirow{5}{*}{$\mathrm{R} 720$} & Chl a & $3.93 \pm 0.01 \mathrm{~d}$ & $4.15 \pm 0.19 \mathrm{c}$ & $3.74 \pm 0.03 \mathrm{e}$ & $4.44 \pm 0.05 b$ & $4.27 \pm 0.02 \mathrm{c}$ & $4.65 \pm 0.01 \mathrm{a}$ \\
\hline & Chl b & $1.83 \pm 0.04 \mathrm{a}$ & $1.85 \pm 0.07 \mathrm{a}$ & $1.75 \pm 0.10 \mathrm{a}$ & $1.99 \pm 0.03 \mathrm{a}$ & $1.86 \pm 0.03 \mathrm{a}$ & $2.06 \pm 0.04 \mathrm{a}$ \\
\hline & Chl a+b & $5.76 \pm 0.05 \mathrm{de}$ & $6.01 \pm 0.25 \mathrm{~cd}$ & $5.50 \pm 0.13 \mathrm{e}$ & $6.43 \pm 0.08 \mathrm{ab}$ & $6.13 \pm 0.05 b c$ & $6.72 \pm 0.05 \mathrm{a}$ \\
\hline & $\mathrm{chl} \mathrm{a/chl} \mathrm{b}$ & $2.20 \pm 0.08 \mathrm{a}$ & $2.24 \pm 0.08 \mathrm{a}$ & $2.15 \pm 0.03 \mathrm{a}$ & $2.23 \pm 0.02 \mathrm{a}$ & $2.30 \pm 0.02 \mathrm{a}$ & $2.26 \pm 0.04 \mathrm{a}$ \\
\hline & Car & $0.71 \pm 0.02 b$ & $0.74 \pm 0.02 \mathrm{~b}$ & $0.75 \pm 0.01 \mathrm{~b}$ & $0.84 \pm 0.01 \mathrm{a}$ & $0.73 \pm 0.04 \mathrm{~b}$ & $0.84 \pm 0.04 \mathrm{a}$ \\
\hline \multirow{5}{*}{$\mathrm{R} 727$} & Chl a & $3.43 \pm 0.03 \mathrm{~d}$ & $3.89 \pm 0.29 b c$ & $3.99 \pm 0.09 b$ & $3.47 \pm 0.21 \mathrm{~d}$ & $3.66 \pm 0.02 \mathrm{~cd}$ & $4.47 \pm 0.18 \mathrm{a}$ \\
\hline & Chl b & $1.56 \pm 0.02 \mathrm{c}$ & $1.66 \pm 0.09 b c$ & $1.62 \pm 0.02 b c$ & $1.52 \pm 0.02 \mathrm{c}$ & $1.73 \pm 0.01 \mathrm{ab}$ & $1.83 \pm 0.02 \mathrm{a}$ \\
\hline & Chl a+b & $4.99 \pm 0.05 \mathrm{c}$ & $5.55 \pm 0.37 \mathrm{~b}$ & $5.61 \pm 0.10 \mathrm{~b}$ & $4.99 \pm 0.22 \mathrm{c}$ & $5.38 \pm 0.03 b c$ & $6.30 \pm 0.19 \mathrm{a}$ \\
\hline & $\mathrm{chl} \mathrm{a/chl} \mathrm{b}$ & $2.20 \pm 0.06 \mathrm{bc}$ & $2.35 \pm 0.10 \mathrm{ab}$ & $2.46 \pm 0.06 \mathrm{a}$ & $2.29 \pm 0.06 \mathrm{abc}$ & $2.12 \pm 0.01 \mathrm{c}$ & $2.44 \pm 0.09 \mathrm{a}$ \\
\hline & Car & $0.58 \pm 0.03 \mathrm{c}$ & $0.65 \pm 0.04 \mathrm{~b}$ & $0.68 \pm 0.01 \mathrm{ab}$ & $0.56 \pm 0.04 \mathrm{c}$ & $0.50 \pm 0.04 \mathrm{~d}$ & $0.74 \pm 0.04 \mathrm{a}$ \\
\hline
\end{tabular}

Note: Data in the table are mean \pm SD of three biological replicates. Different letters indicate significant difference at P $<0.05$ by Dunnett's test, using DPS 7.05 software. Chl a $、 \mathrm{Chl} \mathrm{b} 、$ Car represent chlorophyll a, chlorophyll b and carotenoid, respectively. 
M. oryzae conidia of five physiological races reduced Chl a content of R720, decreasing by $4.52 \%-19.57 \%$, and the $\mathrm{Chl} \mathrm{b}$ was similar or slightly lower than the control group. The conidia affected significantly to the Car content of R720 except for ZG1, all of them were decreasing by $15.48 \%, 11.90 \%, 10.71 \%$ and $13.10 \%$, respectively.

Chl a content of R727 treated by ZF2 decreased, however, Chl $b$ was similar to the control, so $\mathrm{Chl} a / b$ decreased the most greatly about $13.11 \%$. Car content of leaves decreased by $61.62 \%, 12.16 \%, 24.32 \%$ and $32.43 \%$ treated by ZA5, ZA17, ZG1 and ZF2, respectively. The change of $\mathrm{Chl}$ a content is similar with the Pn. It shows the function of $\mathrm{Chl}$ a to photosynthesis is more important. As other result shows that in photosynthesis, the role of vast majority of chlorophyll is to absorb and transfer light energy, only a handful of Chl a transform the light energy [13].

\section{CONCLUSION}

Photosynthesis of plants was inhibited by stomatal and non-stomatal factors under stress [12]. Our result showed that, the $M$. oryzae conidia of five physiological races reduced Pn and Gs of leaves to some extent, but the $\mathrm{Ci}$ of leaves were similar or slightly higher than the control, suggesting that the conidia would affect the stoma and harmed some photosynthetic components in some way. For example, the Pn of R725 was decreased significantly treated by M. oryzae conidia of ZA5 or ZA17. We inferred it caused not only the low Gs resulted in the deficiency of $\mathrm{CO} 2$ supply but also the conidia had inhibited photochemical activity to hinder $\mathrm{CO} 2$ utilization, which resulted in accumulation of intercellular $\mathrm{CO} 2$. It was similar with previous study [14].

Photosynthetic pigment was the material basis of photosynthesis, whose content reflects the level under the stress in plants [15]. Chl a and Chl b were responsible for capture and transmission of light energy mainly, and a few Chl a molecule at special state converts light energy into electrical energy during the process of photosynthesis [16]. In our study, $\mathrm{M}$. oryzae conidia could reduce $\mathrm{Chl} \mathrm{a,} \mathrm{Chl} \mathrm{b}$, $\mathrm{chl} \mathrm{a} / \mathrm{chl} \mathrm{b}$ at the tillering stage, resulting in low efficiency of light absorption and transmission and inhibition of photosynthesis. Car, the important part of light absorption complex, was an important class of antioxidant and could reduce injury of photoinhibition and active oxygen in plants [17]. Our results indicated that Car in leaves were inhibited by conidia of five races in different degree, resulting in diminished capacity of light absorption and radical scavenging, decreased its protection to chlorophyll, and then affected the photosynthetic efficiency.

Photosynthesis and photosynthetic pigment content of one race in different cultivated rice and that of different races in the same cultivated rice were different significantly' which was consistent with the results relating to the study of activity of defense enzymes and virulence genes [18], [19], suggesting that the response of rice variety was statistically different for various physiological races of $\mathrm{M}$. oryzae. It was also consistent with the result of the study that there are different resistance genes of rice blast in different rice variety [20]. According to the association of the races and rice varieties, agronomist can change cultivation practices in a timely manner to improve the disease resistance of rice plants and reduce the use of chemical pesticides, which is of great importance for environmental protection.

\section{REFERENCES}

[1] L. Xiao, J. X. Jiang, Z. L. Yi et al., "Present status and prospect of molecular breeding for blast resistance," Acta Agriculturae, Boreali-occidentalis Sinica, vol. 15, no. 1, pp. 79-84, 2006.

[2] Q. Liu, L. Yin, and W. W. Long, "Effects of aluminum stress on growth and characters of photosynthesis and transpiration in polygonaceae plants," Guihaia, vol. 31, no. 2, pp. 227-232, 2011.

[3] F. Rada, C. Garcla-Nunez, C. Boero, et al., "Resistance against low-temperature resistance in Polylepsis tarapacana, a tree growing at the highest altitudes in the world," Plant Cell and Environment, vol. 24, no. 1, pp. 377-381, 2000.

[4] C. Zhong, Y. Wang, and Z. Y. Chen, "Effects of ultraviolet-B radiation on plant photosynthetic apparatus and processes of photosynthesis," Journal of Yunnan Agricultural University, vol. 24, no. 6, pp. 895-903, 2009.

[5] X. C. Zhang, F. S. Zhang, X. F. Yu, et al., "Effects of nitrogen nutrition on photosynthetic functions of wheat leaves under elevated atmospheric $\mathrm{CO}_{2}$ concentration," Acta Agronomica Sinica, vol. 36, no. 8, pp. 1362-1370, 2010.

[6] T. Uehara and S. Arase, "Primary effects of Magnaporthe grisea toxin(s) on mitochondria of rice leaf cells," Ann.Phytopathol, vol. 63, no. 1, pp. 29-35, 1997.

[7] Y. G. Hu, C. H. Xie, G. T. Yang, et al., "Effect of toxins from cav on physiological and biochemical indexes of rice," Hubei Agricultural Sciences, vol. 50, pp. 4-8, 2011

[8] X. K. Wang, Principles and Techniques of Plant Physiological Biochemical Experiment, Beijing: Higher Education Press, 2006, pp. 134-136.

[9] F. J. Meng, Plant Physiology, Wuhan: Huazhong University of Science and Technology Press, 2000, pp. 77-103.

[10] R.C. Pan, Plant Physiology, Higher Education Press, Beijing, 2004, pp. 17-21.

[11] G. Cornic, J. M. Brlantaris, "Partitioning of photosynthetic electron flow between $\mathrm{CO}_{2}$ and $\mathrm{O}_{2}$ reduction in a $\mathrm{C}_{3}$ leaf (Phaseolus vulgaris L.) at different $\mathrm{CO}_{2}$ concentrations and during drought stress," Planta, vol. 183, pp. 178-184, 1991.

[12] A. M. Lai, S. B. Ku, and G. E. Edwrds, "Analysis of inhibition of photosynthesis due to water stress in the $\mathrm{C}_{3}$ species Hordeum vulgare and Vicia $\mathrm{f}$ aba: electron transport, $\mathrm{CO}_{2}$ fixation and carboxylation capacity," Photosynth Res, vol. 49, pp. 57-69, 1996.

[13] Q. P. Xia, H. B. Gao, and J. R. Li, "Effects of $\gamma$-aminobutyric acid on the photosynthesis and chlorophyll fluorescence parameters of muskmelon seedlings under hypoxia stress," Chinese Journal of Applied Ecology, vol. 22, pp. 999-1006, 2011.

[14] H. X. Xu, X. Y. Weng, W. H. Mao, et al., "Effects of cadmium stress on photosynthesis,chlorophyll fluorescence characteristics and excitation energy distribution in leaves of rice," ChineseJ Rice Sci, vol. 19, no. 4, pp. 338-342, 2005.

[15] Q. P. Xia, H. B. Gao, and J. R. Li. "Effects of $\gamma$-aminobutyric acid on the photosynthesis and chlorophyll fluorescence parameters of muskmelon seedlings under hypoxia stress," Chinese Journal of Applied Ecology, vol. 22, no. 4, pp. 999-1006, 2011.

[16] H. S. Li, Modern Plant Physiology, 2nd ed. Beijing, China: Higher Education Press, 2006, ch. 5, pp. 145-147.

[17] Z. A. Huang, D. A. Jiang, Y. Yang, et al., "Effects of nitrogen deficiency on gas exchange, chlorophyll fluorescence, and antioxidant enzymes in leaves of rice plants," Photosynthetica, vol. 42, no. 1, pp. 357-364, 2004.

[18] L. A. Guo, L. Zhang, Y. G. Hu, et al., "Influence of crude magnaporthegrisea toxin physiology and biochemistry of rice seedlings," Guizhou Agricultural Science, vol. 39, pp. 105-107, 2011.

[19] J. H. Fan, H. P. Zhou, H. H. Wang, et al., "M. grisea physiological races and its toxicity," Plant Protection, vol. 31, pp. 29-31, 2005.

[20] Z. G.. E., L. Q. Zhang, G. A. Jiao, et al., "Highlights in identification and application of resistance genesto rice blast," Chinese J Rice Sci, vol. 22, no. 5, pp. 533-54, 2008. 


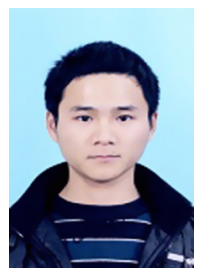

Jun Yi was born in Chengdu of China, the date of birth was August $16^{\text {th }}, 1989$, earned the Bachelor of Agriculture in southwest university of science and technology in 2012. Now, he is a postgraduate of southwest university of science and technology, mainly engaged in rice breeding.

Yungao Hu was born in Mianyang of China, the date of birth was December $28^{\text {th }}, 1963$. He is a postgraduate tutor, as a Research Fellow, mainly engaged in rice genetics breeding, rice heterosis theory and application research. Up to now he had rearched 23breeding hybrid rice variety.
Ling Zhang was born in Mianyang of China, the date of birth was July $27^{\text {th }}$ 1959. She is a Professor, mainly engaged in rice genetics breeding, published over 20papers.

Guotao Yang was born in Shandong of China, the date of birth was January $3^{\text {rd }}, 1982$, earned the Master of Science Degree in southwest university of science and technology in 2012. He is a Research Assistant. He mainly engaged in rice genetics breeding, rice heterosis theory and application research, published over 10 papers.

Liqiong Tang was born in Chengdu of China, the date of birth was September $4^{\text {th }}, 1987$, earned the Bachelor of Agriculture in southwest university of science and technology in 2010. Now, is a postgraduate of southwest university of science and technology, mainly engaged in rice breeding. 